\title{
Shot-Gun Proteomic Analysis on Roots of Arabidopsis plda1 Mutants Suggesting the Involvement of PLD $\alpha 1$ in Mitochondrial Protein Import, Vesicular Trafficking and Glucosinolate Biosynthesis
}

\author{
Tomáš Takáč ${ }^{1}\left(\mathbb{D}\right.$, Olga Šamajová ${ }^{1}$, Pavol Vadovič ${ }^{1}{ }^{10}$, Tibor Pechan ${ }^{2}$ and Jozef Šamaj ${ }^{1, *}$ \\ 1 Centre of the Region Haná for Biotechnological and Agricultural Research, Faculty of Science, \\ Palacký University, Šlechtitelů 27, 78371 Olomouc, Czech Republic; tomas.takac@upol.cz (T.T.); \\ olga.samajova@upol.cz (O.Š.); pavol.vadovic@upol.cz (P.V.) \\ 2 Institute for Genomics, Biocomputing \& Biotechnology, Mississippi Agricultural and Forestry Experiment \\ Station, Mississippi State University, Starkville, MS 39759, USA; pechan@ra.msstate.edu \\ * Correspondence: jozef.samaj@upol.cz; Tel.: +420-585634978
}

Received: 19 November 2018; Accepted: 21 December 2018; Published: 26 December 2018

\begin{abstract}
Phospholipase D $\alpha 1$ (PLD $\alpha 1$ ) belongs to phospholipases, a large phospholipid hydrolyzing protein family. PLD $\alpha 1$ has a substrate preference for phosphatidylcholine leading to enzymatic production of phosphatidic acid, a lipid second messenger with multiple cellular functions. PLD $\alpha 1$ itself is implicated in biotic and abiotic stress responses. Here, we present a shot-gun differential proteomic analysis on roots of two Arabidopsis pld 1 mutants compared to the wild type. Interestingly, PLD $\alpha 1$ deficiency leads to altered abundances of proteins involved in diverse processes related to membrane transport including endocytosis and endoplasmic reticulum-Golgi transport. PLD $\alpha 1$ may be involved in the stability of attachment sites of endoplasmic reticulum to the plasma membrane as suggested by increased abundance of synaptotagmin 1 , which was validated by immunoblotting and whole-mount immunolabelling analyses. Moreover, we noticed a robust abundance alterations of proteins involved in mitochondrial import and electron transport chain. Notably, the abundances of numerous proteins implicated in glucosinolate biosynthesis were also affected in $p l d \alpha 1$ mutants. Our results suggest a broader biological involvement of PLD $\alpha 1$ than anticipated thus far, especially in the processes such as endomembrane transport, mitochondrial protein import and protein quality control, as well as glucosinolate biosynthesis.
\end{abstract}

Keywords: phospholipase D alpha1; Arabidopsis; proteomics; mitochondrial protein import; quality control; vesicular transport; cytoskeleton

\section{Introduction}

Phospholipases are phospholipid hydrolyzing enzymes with multiple roles in biotic and abiotic stress responses of plants as well as in plant growth and development [1]. Phospholipase D (PLD) alpha $1(\mathrm{PLD} \alpha 1)$ is a member of $\mathrm{D}$ subfamily of phospholipases and it shows the highest expression levels among all twelve PLD members in Arabidopsis [2]. Total PLD activity is substantially decreased in Arabidopsis pld $\alpha 1$ mutants [3]. PLDs utilize preferentially phosphatidylcholine as a substrate, which they hydrolyze in $\mathrm{Ca}^{2+}$ dependent manner [2]. This hydrolysis is accompanied with the production of phosphatidic acid (PA), a second messenger bearing important signaling functions [4]. The absence of PLD $\alpha 1$ leads to the reduction of cellular PA pool and membrane lipid 
remodeling [5,6]. This remodeling affects physical and mechanical properties of membranes leading to endomembrane reorganizations and changes in membrane transport [7,8]. PLD $\alpha 1$ is also involved in the regulation of cytoskeletal dynamics and organization, which is either mediated by PA or by direct binding/association of PLD $\alpha 1$ with the cytoskeleton [3,9-12]. PLD $\alpha 1$ promotes stomata closure and inhibits their opening [13]. At a molecular level, stomatal movements are governed by PLD $\alpha 1$ through interaction of PA with protein phosphatase 2C (ABI1) [5], NADPH oxidase [14], sphingosine kinase [15] and microtubule associated protein 65-1 [3]. In addition, PLD $\alpha 1$ binds and modulates components of $G$ protein complex during stomatal movements $[16,17]$. These functions render PLD $\alpha 1$ an important regulator of the plant stress response, growth and development. PLD $\alpha 1$ was shown to be involved in plant response to drought [18], cold [19] and salt stress [12]. This protein has promising biotechnological applications, since its genetic manipulation modulates plant response to abiotic stresses [20]. Nevertheless, PLDs usually act cooperatively (including the production of cellular PA pool), as it was previously exemplified in abscisic acid (ABA)-induced stomatal closure [21]. Arabidopsis mutants of $P L D \alpha 1$ exhibit conditional phenotypes, whereas under control conditions they show phenotypes similar to the wild-type plants [3,22]. Recent detailed fluorescent in vivo imaging of PLD $\alpha 1$ fused to YFP and expressed in Arabidopsis PLD $\alpha 1 \mathrm{t}$-DNA insertion mutants under its own promoter showed that PLD $\alpha 1-Y F P$ localized to the cytoplasm in the close vicinity of plasma membrane (PM) and exerted developmentally-dependent and tissue-specific expression [12]. Interestingly, most of PLD $\alpha 1$ functions are assigned to processes occurring in leaves. On the other hand, PLD $\alpha 1$ functions in roots are obscure. Shot gun proteomic analysis on genetically modified plants proved to be very useful tool for elucidation of protein functions. Here, we performed a comparative shot gun proteomic analysis on roots of two t-DNA insertion mutants (pld $\alpha 1-1$ and pld $\alpha 1-2)$ as compared to the Col-0 wild type. Our results indicated that PLD $\alpha 1$ is involved in mitochondrial protein import and quality control, glucosinolate biosynthesis and that it controls very specific processes of subcellular vesicular transport.

\section{Results}

\subsection{Overview of Differential Root Proteomes in Two plda1 Mutants}

We carried out a comparative shot-gun proteomic analysis of roots of two pld $\alpha 1$ mutants compared to the Col-0 as a wild type. First, we compared the number of identified proteins (Figure S1A) and peptides (Figure S1B) in Col-0, pld $\alpha 1-1$ and pld 1 1-2 mutants showing high reproducibility of our analysis (Figure S1A). Considering proteins identified at least in 2 biological replicates, $92 \%, 82 \%$ and $75 \%$ of the total proteomes of Col-0, pld $\alpha 1-1$ and pld $\alpha 1-2$ roots were found commonly in all three lines (Figure S1C). In pld 1 1-1, 92 proteins with changed abundances were found, while 113 were identified in plda1-2 mutant (Figure 1A). In both mutants, 32 proteins were commonly changed (Figure 1B, Table 1). PLD $\alpha 1$ was identified uniquely in the wild type, while we did not detect this protein in two studied mutants, confirming the reliability of our approach. Similarly, we were unable to detect PLDrp1 (PLD regulated protein 1; At5g39570), a phosphoprotein interacting with PLD $\alpha 1$ [23], in pld $\alpha 1$ mutants. A complete list of all differentially abundant proteins (DAPs) of both mutants is available in Table S1. A detailed outputs of protein identification in all samples is presented in the Supplementary Materials, and deposited in PRoteomics IDEntifications (PRIDE) database (see below).

Table 1. List of differentially abundant proteins found commonly in roots of both pld $\alpha 1-1$ and pld $\alpha 1-2$ mutants as compared to the wild type (WT). n.a. = not applicable.

\begin{tabular}{ccccccc}
\hline $\begin{array}{c}\text { TAIR } \\
\text { Accession } \\
\text { Number }\end{array}$ & $\begin{array}{c}\text { UNIPROT } \\
\text { Accession } \\
\text { Number }\end{array}$ & Sequence Name & $\begin{array}{c}\text { plda1-1/ } \\
\text { Col-0 } \\
\text { Ratio }\end{array}$ & $\begin{array}{c}p l d \alpha 1-2 / \\
\text { Col-0 } \\
\text { Ratio }\end{array}$ & $\begin{array}{c}p l d \alpha 1-1 / \\
\text { Col-0 } \\
p \text { Value }\end{array}$ & $\begin{array}{c}p l d \alpha 1-2 / \\
\text { Col-0 } \\
p \text { Value }\end{array}$ \\
\hline Q8LD46 & At2g39460 & Translation & & & & \\
\hline Q9LHG9 & At3g12390 & $\begin{array}{c}\text { Nascent polypeptide-associated complex subunit } \\
\text { alpha-like protein 1 }\end{array}$ & 1.82 & 1.91 & 0.052 & 0.029 \\
\hline
\end{tabular}


Table 1. Cont.

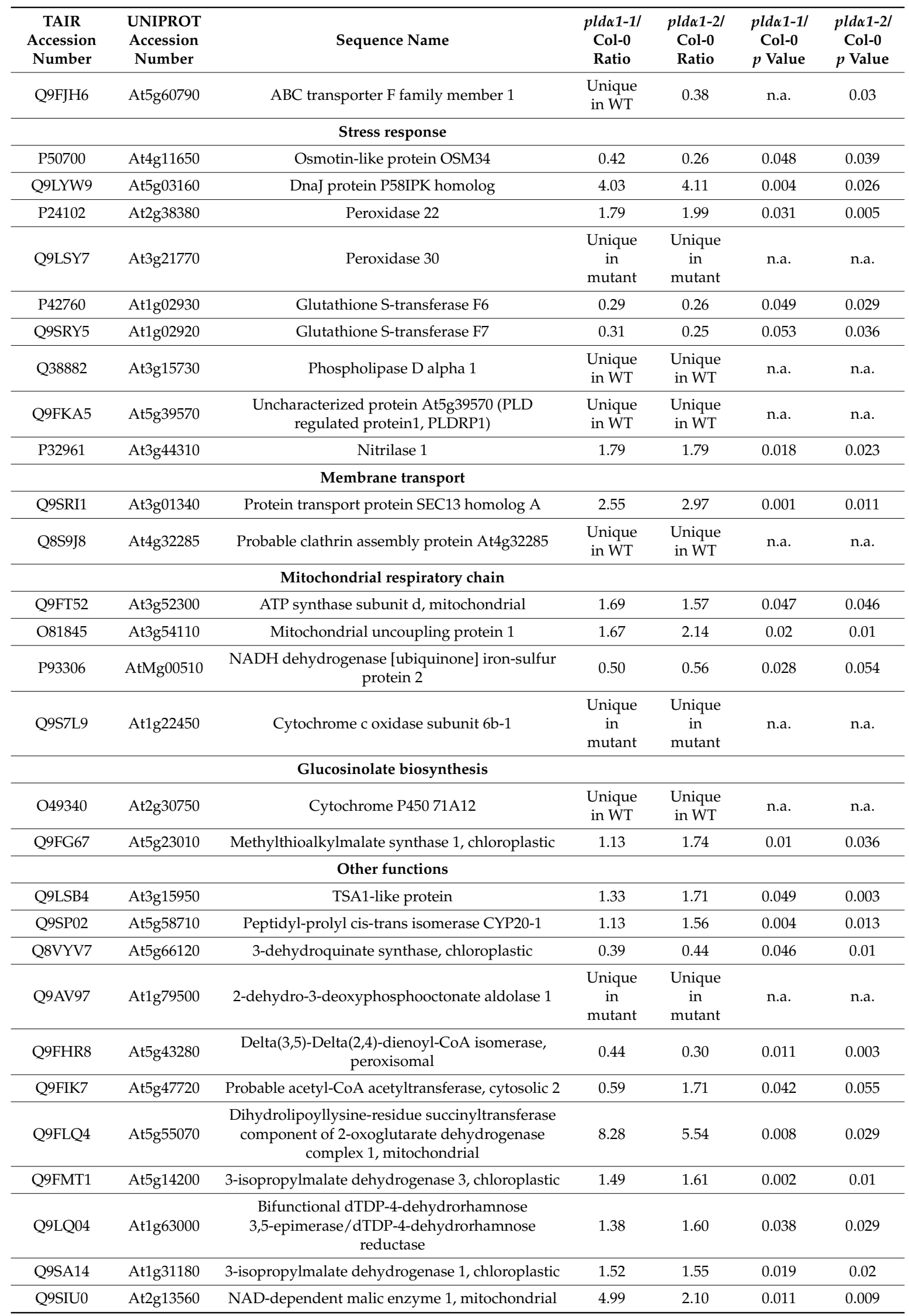


A

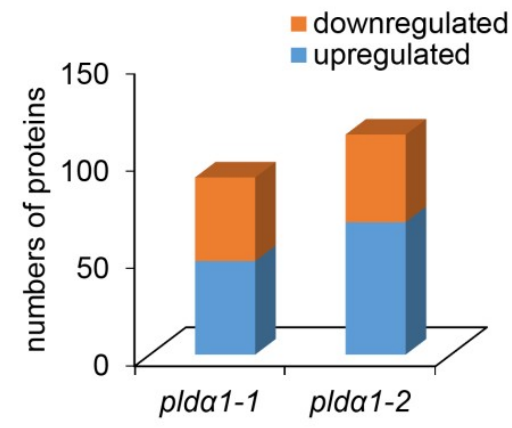

B

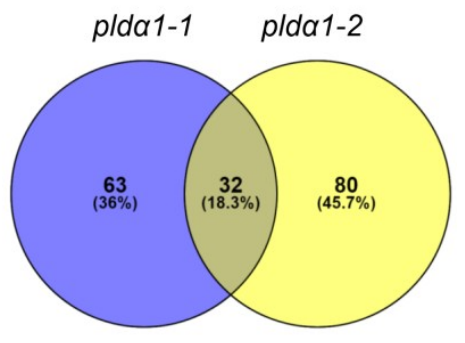

Figure 1. Overview of differential root proteomes of pld $\alpha 1$ mutants. (A) Numbers of proteins with increased and decreased abundances in pld 1 1-1 and pld 1 1-2 mutant. (B) Venn diagram showing difference between differential proteomes the pld $\alpha 1-1$ and $p l d \alpha 1-2$.

\subsection{Classification of Root Differential Proteomes in pld $\alpha 1$ Mutants}

A Kyoto encyclopedia of genes and genomes (KEGG) pathways analysis is a reasonable tool for the evaluation of proteins involved in metabolism. The highest number of DAPs was classified into the purine metabolism pathway and biosynthesis of antibiotics. Several proteins affected in both mutants are involved in pyruvate metabolism, amino acid biosynthesis and metabolism and phenylpropanoid biosynthesis (Figure 2).

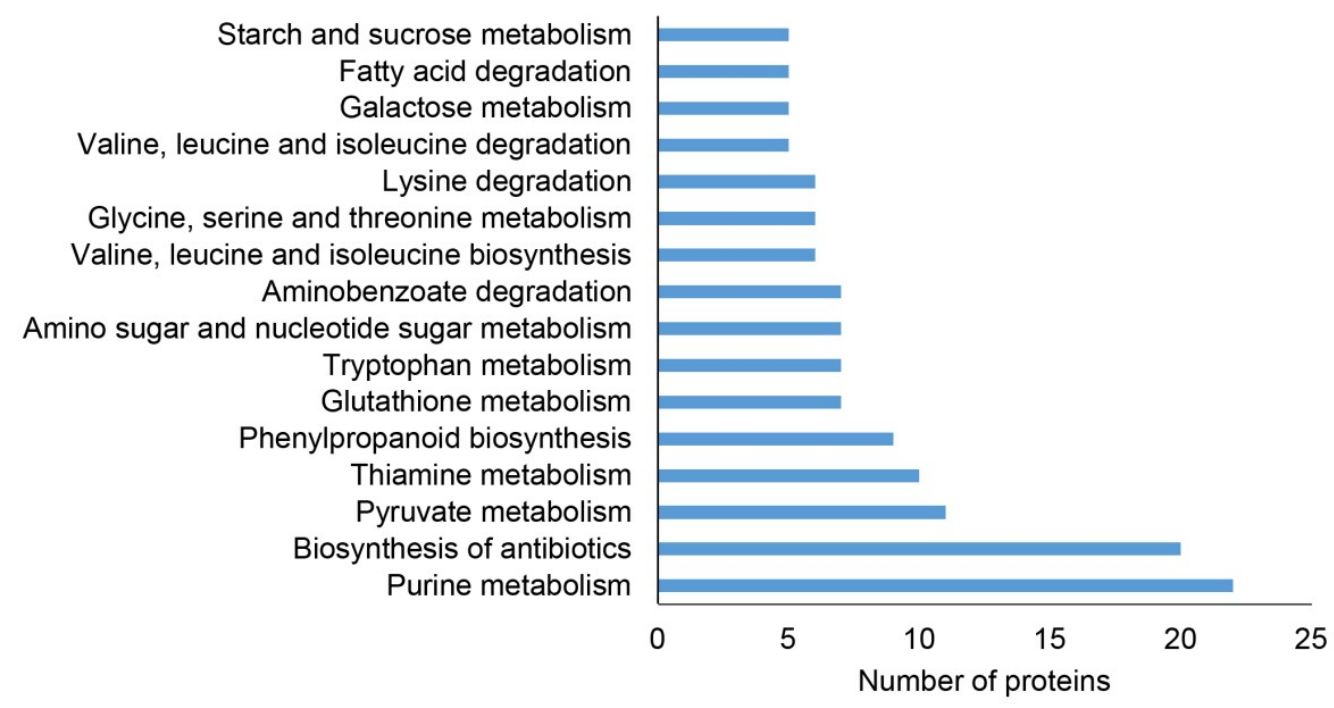

Figure 2. Functional classification of differentially abundant proteins found collectively in roots of pld 1 1-1 and pld 1 1-2 mutants using Kyoto Encyclopedia of Genes and Genomes (KEGG) pathways analysis.

Additionally, we screened differential proteomes of both mutants for the abundance of protein families, as evaluated by the Blast2Go software using InterPro application (Figure 3, Table S2). We identified nine proteins belonging to the $\mathrm{NAD}(\mathrm{P})$ binding protein superfamily, while seven proteins belonged to the Winged helix DNA-binding domain superfamily. Later ones include proteins with different functions (Table S2) and possessed specific DNA binding mechanisms different from sequence specific binding. They display an exposed patch of hydrophobic residues implicated in protein-protein interactions [24]. The peroxidases and aldolase-type TIM (triose phosphate isomerase) barrel protein family represented abundant protein classes found in both pld $\alpha 1$ mutants (Figure 3, Table S2). These proteins might show higher sensitivity to PLD $\alpha 1$ and PA deregulation in Arabidopsis. 


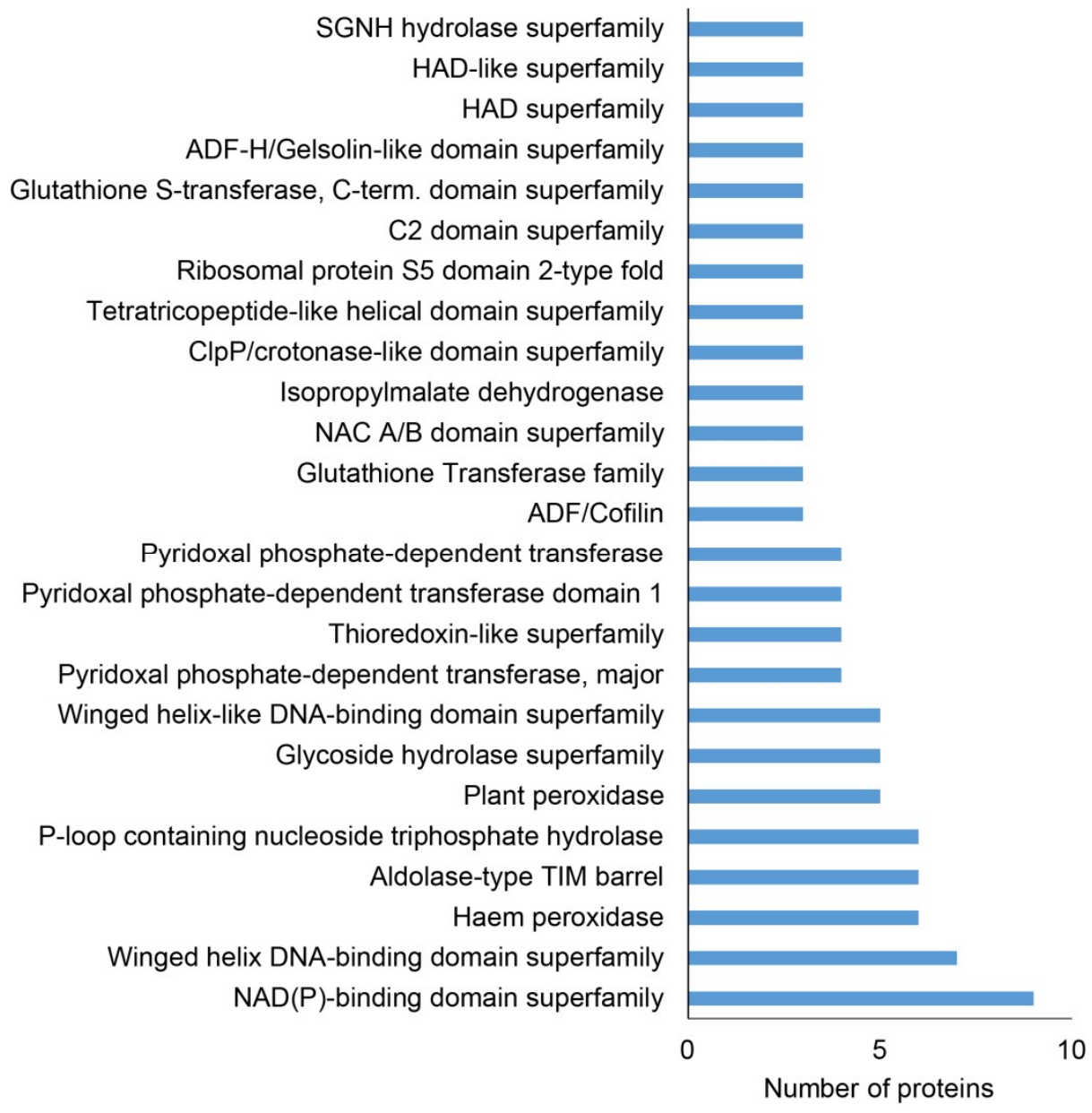

Figure 3. Distribution of protein families, in differentially abundant proteins found collectively in roots of pld 1 1-1 and pld 1 1-2 mutants, as evaluated by InterPro application of Blast2Go software. $\mathrm{HAD}=$ haloacid dehydrogenase; $\mathrm{ADF}=$ actin depolymerization factor; $\mathrm{TIM}=$ mitochondrial import inner membrane translocase; NAC = nascent polypeptide-associated complex; SGNH = serin, glycin, asparagine, histidin.

Furthermore, we classified differential proteomes of pld $\alpha 1$ mutants (combined) using a gene ontology (GO) annotation analysis. The highest number of the DAPs was assigned to metabolic processes and nitrogen compound metabolic processes. A significant number of DAPs were involved in response to stress as well as establishment of localization (Figure S2A). Higher levels of GO revealed that proteins annotated as involved in stress response belong to GO class called response to osmotic stress (Table S3). Concerning cellular compartment, the GO ontology analysis showed that the highest number of DAPs was assigned to cytosol, followed by plastid, mitochondria, protein complex and the nucleus (Figure S2B).

Since GO ontology analysis does not consider all relevant information about protein functions, we decided to classify the combined differential proteome based on published data (Figure 4, Table 1 and Table S1).

Apart from the high number of DAPs with diverse metabolic functions, proteins related to the stress response were the second most abundant category (Figure 4, Table S1). Notably, PLD $\alpha 1$ deficiency in both mutants negatively affected the abundance of protein C2-domain ABA-related 10 (CAR10), a component of the pyrabactin resistance1/pyrabactin resistance1-like/car (PYR/PYL/CAR) receptors for ABA [25]. Additionally, we noticed the significant disturbance of antioxidant defense and redox homeostasis. This is represented by the increased abundance of ironic superoxide dismutase 1 (FeSOD1), ascorbate peroxidase and peptide methionine sulfoxide reductase B6. Secretory peroxidases 
exhibited varying changes in protein abundance, while catalase and glutathione S-transferase F7 had a lower abundance in the mutants compared to the wild type. To prove the increased abundance of FeSOD1, we performed an immunoblotting analysis on pld $\alpha 1$ mutants using anti-FeSOD1 polyclonal primary antibody (Figure 5A,B). The Arabidopsis thaliana genome contains three isoforms of FeSOD, out of which FeSOD2 and FeSOD3 are not expressed in the roots. Therefore, anti-FeSOD antibody recognizes FeSOD1 in the Arabidopsis roots. These analyses showed significant upregulation of FeSOD1 abundance in both $p l d \alpha 1$ mutants.

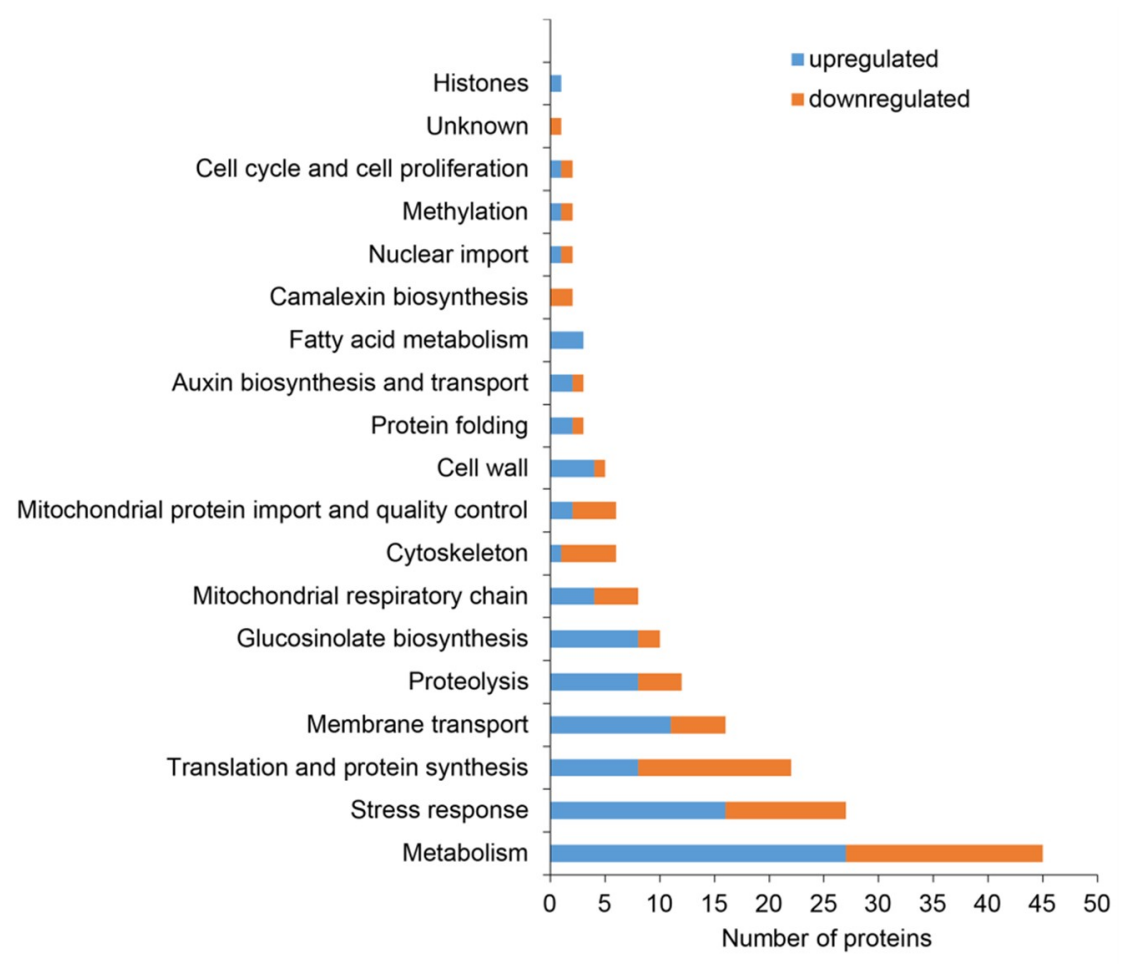

Figure 4. Functional classification of differentially abundant proteins found collectively in roots of pld $\alpha 1-1$ and pld $\alpha 1-2$ mutants based on published information, as presented in Table S1.

Interestingly, PLD $\alpha 1$ deficiency also leads to deregulation of proteins involved in cell wall remodeling (Figure 4, Table S1), which represents one of the primary plant defense responses to pathogens. This is consistent with the known role of PLD $\alpha 1$ in plant biotic stress [26]. Furthermore, we have found several defense related proteins differentially abundant in the $p l d \alpha 1$ mutants, including secretory peroxidases, nitrile specifier protein 1 and defensin-like protein 1 (Table S1). The majority of these proteins show increased abundance in the mutants. Notably, proteins involved in glucosinolate biosynthesis (discussed below) are highly represented, showing mostly increased abundances in the mutants (Figure 4).

Additionally, we have found numerous proteins involved in membrane fusion and transport. They are described in detail in the Discussion section. Among others, a PLD $\alpha 1$ deficiency resulted in accumulation of synaptotagmin 1 in the mutants. These proteomic data were successfully validated using immunoblotting analyses (Figure 5C,D) and immunolocalization of the syntaptotagmin 1 (SYT1) protein in intact roots showing an increased accumulation in both pld $\alpha 1$ mutants (Figure 6).

Proteins involved in ribosome biogenesis and translation, mitochondrial respiration, mitochondrial protein import and quality control represented a significant functional classes altered by PLDa1 deficiency (Figure 4, Table 1 and Table S1). These findings might indicate defects of cytosolic translation and mitochondrial protein import resulting in changed abundances of mitochondrial proteins. Therefore we searched for proteins carrying mitochondrial targeting signal among DAPs. We have found 19 proteins with varying changes in their abundance, suggesting an altered homeostasis 
in the import of mitochondrial proteins (Table S4). One of such proteins, mitochondrial uncoupling protein 1 (UPC1) has increased abundance in the mutants, being in agreement with the immunoblotting analysis (Figure 5E,F) and immunolocalization of uncoupling protein 1 (UCP1) protein (Figure 7). In addition, we observed also decreased levels of MORF8 (multiple site organellar RNA editing factor, designated also as RIP1; Table S1), a protein important for mitochondrial mRNA editing. Finally, absence of PLD $\alpha 1$ in both mutants affects also a cluster of components of the mitochondrial respiratory chain. Thus, PLD $\alpha 1$ is likely required for multiple mitochondrial functions in Arabidopsis (Table S1, Figure 4).

A

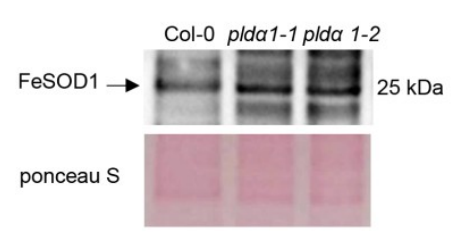

C

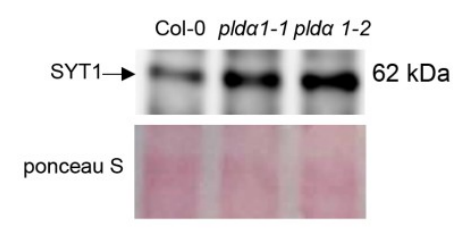

E

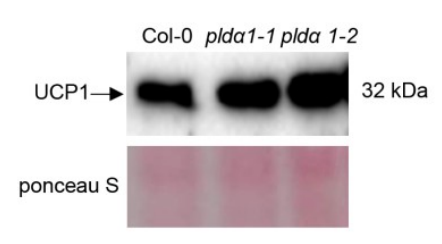

B

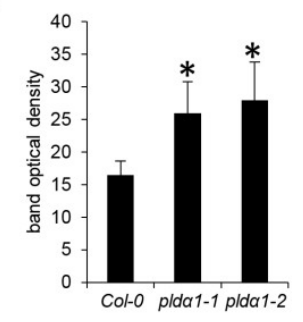

D

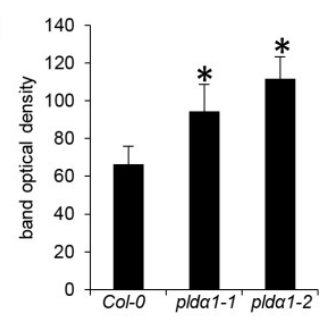

$\mathbf{F}$

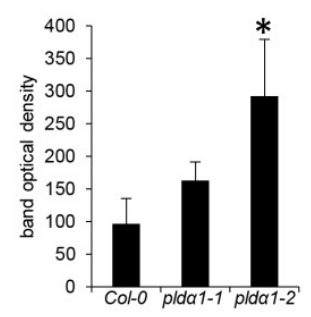

Figure 5. Immunoblotting analysis of ironic superoxide dismutase 1 (FeSOD1), syntaptotagmin 1 (SYT1) and mitochondrial uncoupling protein 1 (UCP1) in the roots of the Arabidopsis wild type and pld 1 mutants. (A,C,E) Immunoblots probed with anti-FeSOD (A), anti-SYT1 (B) and anti-UCP1 (C) antibodies and visualization of proteins transferred on nitrocellulose membranes using Ponceau S. (B,D,F) Optical density quantification of the respective bands in $(\mathbf{A}, \mathbf{C}, \mathbf{E})$. Stars indicate significant differences between mutants and wild type at $p \leq 0.05$ according to the Student $\mathrm{t}$-test. Error bars represent standard deviations.

PLD $\alpha 1$ and PA are important regulators of actin and microtubule cytoskeletons in plants [11,27]. As expected, PLD $\alpha 1$ deficiency in both mutants resulted in differential abundances of actin and microtubule associated proteins, including actin 1 and actin depolymerizing factors (ADFs) 1,8 and 10 (showing decreased abundances in pld $\alpha 1$ mutants) (Table 1 and Table S1). Such results indicate possible disturbances in actin monomer turnover and actin polymerization in pld $\alpha 1$ mutants. Additionally, we identified two protein candidates potentially important for microtubule regulation by PLD $\alpha 1$. Both proteins were detected uniquely in $p l d \alpha 1$ mutants and are involved in tubulin monomer folding. Tubulin-folding cofactor B is a member of the Arabidopsis pilZ domain proteins [28,29]. It interacts with alpha-tubulin and its overexpression results in reduced number of microtubules [30]. Chaperone prefoldin 6 is required for tubulin monomer abundance, microtubule dynamics and organization [31]. 

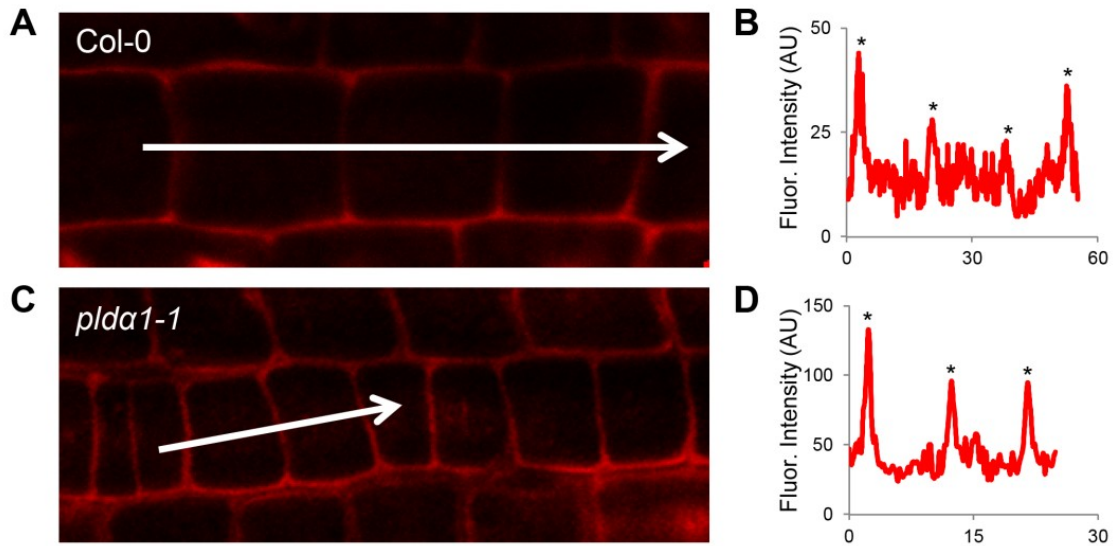

E
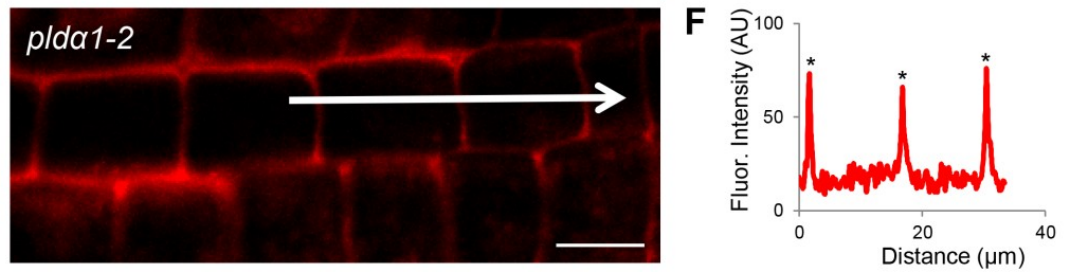

Figure 6. Immunolocalization of synaptotagmin (SYT1) in root epidermal cells of wild type (A), pld 1 1-1 (C) and pld $\alpha 1-2$ (E). (B,D,F) Fluorescence intensity profiles of immunolabeled synaptotagmin distributions in wild type (B), pld $\alpha 1-1$ (D) and pld $\alpha 1-2$ (F). Arrows indicate positions of measured cells for fluorescence intensity profiles. Asterisks indicate peaks of highest fluorescence intensities in measured cells. Note that fluorescence intensities in pld $\alpha 1$ mutants are much higher in comparison to the wild type, indicating overabundance of SYT1 in these mutants. Scale bar $=10 \mu \mathrm{m}$.
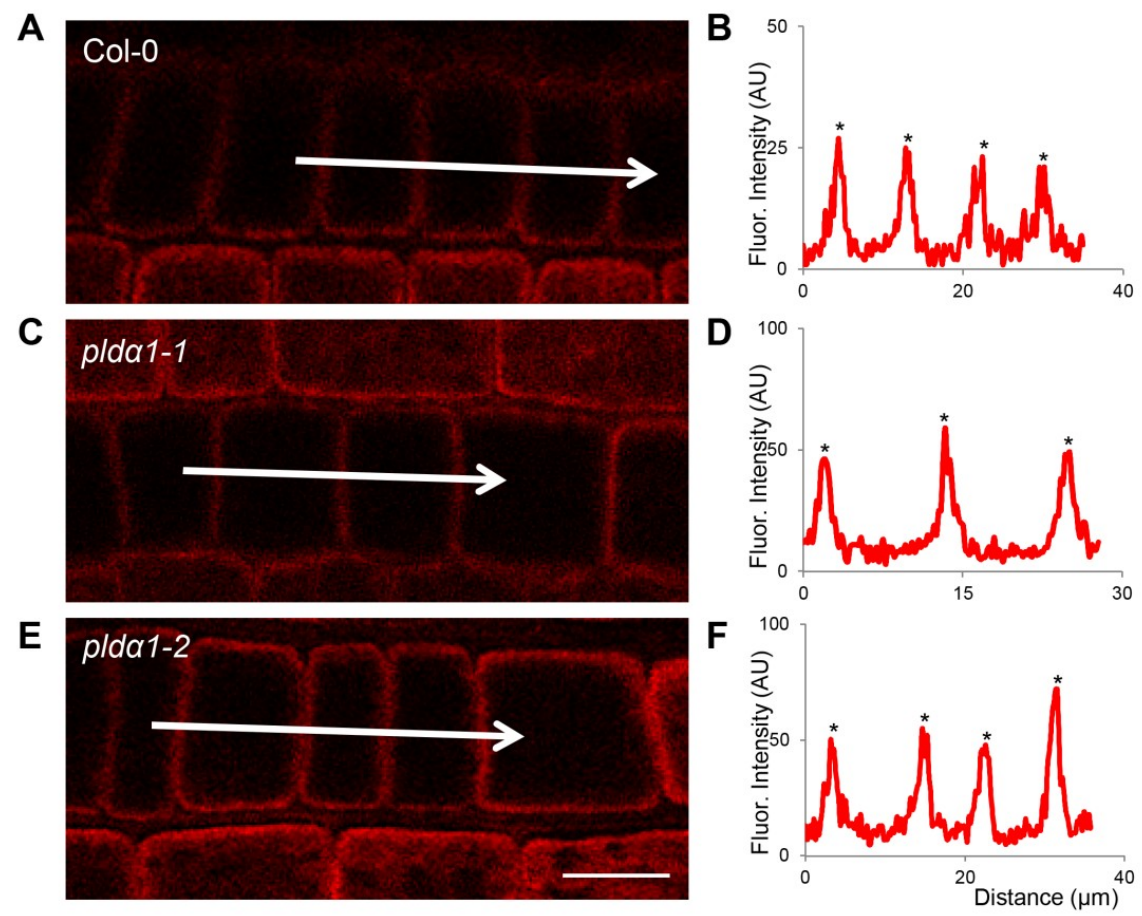

Figure 7. Immunolocalization of mitochondrial uncoupling protein 1 (UCP1) in root epidermal cells of wild type (A), pld $\alpha 1-1$ (C) and pld $\alpha 1-2$ (E). (B,D,F) Fluorescence intensity profiles of immunolabeled synaptotagmin distributions in wild type (B), pld $\alpha 1-1$ (D) and $p l d \alpha 1-2$ (F). Arrows indicate positions of measured cells for fluorescence intensity profiles. Asterisks indicate peaks of highest fluorescence intensities in measured cells. Note that fluorescence intensities in pld $\alpha 1$ mutants are much higher in comparison to the wild type, indicating an overabundance of UCP1 in these mutants. Scale bar $=10 \mu \mathrm{m}$. 


\section{Discussion}

This differential proteomic analysis on roots of $p l d \alpha 1$ mutants revealed that PLD $\alpha 1$ is required for homeostasis of proteins involved in diverse processes. In this study, we focused especially on potential new functions of PLD $\alpha 1$ such as mitochondrial protein import and quality control, vesicular trafficking and glucosinolate biosynthesis. Considering the regulatory and catalytic roles of PLD $\alpha 1$, we assume that besides its lipid hydrolyzing activity, the changes in the proteomes of pld $\alpha 1$ mutants occurred as a consequence of compromised PA, G protein complex and ABA signalling.

\subsection{New Insights into ABA Signalling}

PLD $\alpha 1$ derived PA is a crucial regulator of stomatal movements, because it targets/binds multiple proteins essential for this process, including ABI1 [5], NADPH oxidase [14], G protein complexes [13] and MAP65-1 [3]. Assuming from our results, there seems to be a broader impact on other components of ABA signalling because PLD $\alpha 1$ deficiency negatively affected the abundance of protein C2-DOMAIN ABA-RELATED 10 (CAR10). CAR10 interacts with PYR/PYL ABA receptors and recruits them transiently into phospholipid vesicles, thus positively regulating ABA signaling [25]. The PYR/PYL/CAR receptors also bind to ABI1 [32]. These data indicate a possible feedback regulation of CAR10 abundance in the absence of PLD $\alpha 1$ and decreased levels of PA. In addition, aquaporins PM intrinsic protein 1-2 (PIP1-2) and PIP2-1 are ABA-inducible proteins, which promote water uptake

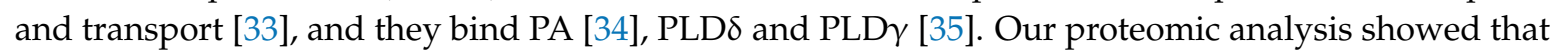
abundances of these proteins substantially increased in $p l d \alpha 1$ mutants.

\subsection{Mitochondrial Protein Import and Quality Control}

According to our results, PLD $\alpha 1$ deficiency in mutants caused a deregulation of proteins involved in protein import to mitochondria, including mitochondrial import inner membrane translocase subunits TIM23-2 and TIM13, which are downregulated. While TIM23-2 is a translocase responsible for the transport of mitochondrial precursor proteins carrying a cleavable N-terminal pre-sequence [36], TIM13 is a member of small TIM complex delivering client precursors that pass through the TOM (mitochondrial import outer membrane translocase) channel to Tim22 in the mitochondrial intermembrane space [37]. Therefore, the import of nucleus-encoded mitochondrial proteins is altered in $p l d \alpha 1$ mutants. Along with altered protein import to mitochondria, PLD $\alpha 1$ deficiency may affect also N-terminal presequence cleavage (inferred by increased abundance of presequence protease 1 in $p l d \alpha 1$ mutants) occurring after protein precursor import into mitochondria [38]. Furthermore, we provided experimental evidence on deregulation of prohibitin 6 involved in mitochondrial protein folding [39]. Prohibitins (PHBs) are considered to be structural proteins that form a scaffold-like structure for interacting with a set of proteins involved in various mitochondrial processes [39]. These proteins participate in the assembly of multi-subunit complexes such as mitochondrial respiratory complex [40]. Accordingly, several proteins of the mitochondrial electron transport chain show significant changes in their abundance in both mutants as compared to the wild type. Mitochondrial protein import machinery was also reported to be in close interaction with the organization of respiratory complexes. Tim23-2 is localized also in respiratory complex 1 and its genetic modification leads to altered transcription of mitochondrial proteins and defective mitochondria biogenesis [36]. A similar role in mitochondria biogenesis was found for prohibitins [41]. Thus far, PLD $\alpha 1$ was not linked to these mitochondrial functions, although the ATP synthase subunit gamma and ADP / ATP carrier protein were targeted by PA in Arabidopsis [34].

\subsection{Vesicular Transport}

PLD-derived PA can regulate membrane transport by direct modification of membrane curvature or by recruiting important regulatory proteins [42]. These proteins positively affect protein internalization [43,44], vesicle fusion and aggregation [45]. In Drosophila, PLD activity couples 
endocytosis with retromer dependent recycling [46]. Our findings indicate that PLD $\alpha 1$ alters multiple sites of endomembrane system. For example, in both mutants we detected decreased abundances of vacuolar $\mathrm{H}^{+}$ATPases (subunits $\mathrm{D}$ and $\mathrm{d} 2$ ), which control multiple events in endomembrane transport by acidification of endomembrane compartments [47].

In accordance with the known involvement of PLDs in vesicle fusions, we observed an increased abundance of alpha-soluble N-ethylmaleimide-sensitive factor (NSF) attachment protein 2 (Alpha-SNAP2) in the plda1-1 mutant. Alpha-SNAP proteins bind the soluble NSF attachment protein receptor (SNARE) complex [48] and are required for the vesicle pre-docking, an initial step of the membrane fusion reaction $[49,50]$. The precise function of alpha-SNAP2 is unknown, though it might require PLD $\alpha 1$. Remarkably, alpha-SNAP2 interacting syntaxin 32 (SYP32), a Golgi localized Qa SNARE [51] was found as upregulated in pld $\alpha 1$ mutants. Thus, PLD $\alpha 1$ might be necessary for SNARE-SNAP protein complexes stability.

We identified several proteins involved in the endocytic pathway as differentially regulated in both pld 1 mutants. These include mainly the probable clathrin assembly protein At4g32285 (not detected in pld 1 mutants), which is involved in clathrin-mediated endocytosis [52]. Clathrin assembly proteins interact directly with proteins of the clathrin coat and are able to bind phospholipids [53]. Two such proteins were identified as PA-binding proteins [34]. Furthermore, PLD $\alpha 1$ localized in the vicinity of clathrin heavy chain and microtubules of Arabidopsis root cells [12] and it may directly bind clathrin in a complex containing adaptor protein-2 (AP-2) [54]. Vacuolar protein sorting 29 (VPS29), a protein found uniquely in the pld $1-1$ mutant, is a component of retromer complex. This is a coat complex localized to the cytosolic face of endosomes and involved in intracellular sorting of some transmembrane proteins [55]. VPS29 is important for normal morphology of prevacuolar compartment (PVC) and plays crucial role in recycling vacuolar sorting receptors from the PVC to the trans Golgi network (TGN) during trafficking of soluble proteins to the lytic vacuole [56,57]. These data uncovers new endocytic proteins affected in $p l d \alpha 1$ mutants.

PLD $\alpha 1$ deficiency in both mutants altered also abundances of proteins involved in the regulation of endoplasmic reticulum (ER) to Golgi transport. Protein transport protein SEC13 homolog A is upregulated nearly threefold in both pld $\alpha 1$ mutants. Sec13 makes a lattice structure together with Sec31 to form COPII vesicles [58], which are responsible for ER to Golgi transport. According to our results, PLD $\alpha 1$ may have also an impact on the morphology of Golgi apparatus, inferred by the upregulation of Golgin candidate 5 (also known as the TATA element modulatory factor) in the pld $\alpha 1-2$ mutant $[59,60]$. Another protein important for ER to Golgi trafficking is vesicle-associated protein 1-2 (PVA12, also known as VAP27-3), which is upregulated in the pld 1 1-1 mutant. This is an ER-localized protein belonging to a VAP27 family [61]. It binds to oxysterol-binding protein-related protein 3B [62], which is also upregulated in the mutants and is proposed to cycle between the ER and the Golgi [62]. Recently, PVA12 was shown to colocalize and interact with Networked 3C (NET3C) at ER-PM contact sites [61]. Considering PLD $\alpha 1$ localization in the PM vicinity, we suggest an involvement of this protein in ER-PM attachment. This is emphasized by an increased abundance of synaptotagmin 1 (SYT1) in pld 1 mutants, representing a protein mediating the ER-PM contacts in Arabidopsis [63].

PLD $\alpha 1$ depletion leads to changed abundance of proteins regulating the membrane transport. Changes in protein level might be a result of deregulation of protein synthesis and proteolysis or transcriptional control. Previously, it was shown that changes in membrane transport might result in changed abundance of proteins. This was exemplified for example in Arabidopsis roots exposed to brefeldin A (BFA), which blocks secretion/exocytosis by aggregation of TGN and PM-derived vesicles surrounded by Golgi stacks into so called BFA-compartments [64]. Altered endocytosis and vacuolar trafficking by wortmannin lead to altered abundances of vacuolar proteases potentially leading to defected protein degradation [65]. Similar downregulation of such protease, subtilisin-like protease SBT1.7 is encountered also in roots of pld $\alpha 1$ mutants. Based on our proteomic data we suggest that this dynamics of membrane transport regulatory processes might result from defected 
protein degradation and as a feedback mechanism of PLD $\alpha 1$ depletion-induced changes in membrane architecture, membrane transport and PA accumulation.

\subsection{Glucosinolate Biosynthesis}

PLDs have been shown to crosstalk with hormonal signaling in plants. In addition to their well-known role in ABA signaling, they also participate in salicylic acid signaling by controlling relocation of NPR1, an essential regulator of SA induced gene transcription, into the nucleus [66]. In addition, PLDs might be activated by cytokinins [67] and ethylene [68]. Constitutive triple response 1 (CTR1), a negative regulator of ethylene response is a potential target of PA [69]. PLDs are also involved in auxin distribution. Thus, PLD $\zeta$-derived PA is required for protein phosphatase $2 \mathrm{Ac}$ (PP2Ac) recruitment to the membrane resulting in altered auxin efflux carrier component 1 (PIN1) phosphorylation and polar distribution [7]. Auxins share an initial steps of biosynthetic pathway with glucosinolates $[70,71]$. Arabidopsis mutants with reduced glucosinolate contents show severe auxin phenotypes [72]. Generally, glucosinolates are secondary messengers produced in Brassicaceae with important defense and developmental functions [70,73]. PLD $\alpha 1$ deficiency in mutants causes increased abundances of enzymes involved in glucosinolate biosynthesis, including four subunits of 3-isopropylmalate dehydrogenase and methylthioalkylmalate synthase, all involved in the chain elongation machinery. Enzymes involved in the biosynthesis of the core glucosinolate structure, namely cytochrome P450 83B1, glutathione S-transferase F9, indole glucosinolate O-methyltransferase 1 and adenylyl-sulfate kinase 1, showed similar trends in their abundances (Table S1). PLD $\alpha 1$ induced an imbalance of indole glucosinolate o-methyltransferase 1 abundance, which is a glucosinolate modifying enzyme [71]. Glutathione synthase 1 showed an increased abundance in mutants, most likely contributing to the glutathione pool, which serves as a sulfur donor within the second stage of GLS biosynthesis [71]. Such differential regulation of enzymes involved in one metabolic pathway in untargeted proteomic approach is very unusual, suggesting that PLD $\alpha 1$ might be a master regulator of glucosinolate biosynthesis. It is likely that this regulation is mediated via PA, since cytochrome P450 $83 \mathrm{~B} 1$ is a PA-binding protein, as identified in a proteomic screen [34].

\section{Materials and Methods}

\subsection{Plant Material}

Seeds of Arabidopsis thaliana wild type (ecotype Col-0) as well as pld 1 1-1 (SALK_067533) and pld $\alpha 1-2$ (SALK_053785) t-DNA insertion mutants were used in this study. Following ethanol surface-sterilization, they were cultivated vertically on solid half-strength Murashige-Skoog (MS) media at $21{ }^{\circ} \mathrm{C}$ under 16/8 light/dark illumination conditions for 14 days. Roots were quickly dissected and harvested for protein extraction. Proteomic analyses were performed in four biological replicates. Roots of 30 seedlings were pooled in one biological replicate.

\subsection{Protein Extraction and Trypsin Digestion}

Samples were ground in liquid nitrogen and subjected to phenol protein extraction followed by ammonium acetate/methanol precipitation as described by Takáč et al. [74]. Cleaned precipitates were dissolved in $6 \mathrm{M}$ urea in $100 \mathrm{mM}$ Tris $(\mathrm{pH} \mathrm{7,8).} \mathrm{Prior} \mathrm{to} \mathrm{trypsin} \mathrm{digestion,} \mathrm{extracts} \mathrm{containing}$ $50 \mu \mathrm{g}$ of proteins (in volume of $50 \mu \mathrm{l})$ were diluted with $100 \mathrm{mM}$ Tris- $\mathrm{HCl}(\mathrm{pH} 7,8)$ to adjust the urea concentration bellow $1 \mathrm{mM}$. Proteins were digested with trypsin (Promega; $1 \mu \mathrm{g}$ of trypsin to $50 \mu \mathrm{g}$ of proteins) at $37^{\circ} \mathrm{C}$ overnight. Reaction was stopped by addition of $4 \mu \mathrm{L}$ of acetic acid. Peptide mixtures were cleaned using C18 gravity flow cartridges (Bond Elut C18; Agilent Technologies, Santa Clara, CA, USA) according to manufacturer's instructions. Peptides eluted by $95 \%$ acetonitrile were dried using vacuum concentrator and stored under $-80^{\circ} \mathrm{C}$ until analysis. 


\subsection{Liquid Chromatography, Mass Spectrometry, Protein Identification and Relative Quantitative Analysis}

Liquid chromatography-MSMS and protein identification was performed as published previously [74] with minor modifications. As target database and decoy databases, the UNIPROT (www.uniprot.org) Arabidopsis genus taxonomy reviewed protein database (17,586 entries as of 31st September 2017), and its reversed copy (created automatically by the software) were used, respectively. The mass spectrometry proteomics data have been deposited to the ProteomeXchange Consortium via the PRIDE partner repository with the dataset identifier PXD011196.

The quantitative analysis was done using the ProteoIQ 2.1 (NuSep Inc., Athens, GA, USA) software as published previously [75]. The ANOVA $p \leq 0.05$ was used to filter statistically significant results. Proteins with fold changes higher than 1.5 were considered as differentially abundant. Proteins present at least in two biological replicates and identified by at least two peptide spectral matches were quantified.

\subsection{Bioinformatic Analysis}

Gene ontology (GO) annotation analysis of DAPs was performed using Blast2Go software [76]. BLAST searching was performed against the Arabidopsis thaliana NCBI database allowing 1 BLAST Hit. The annotation was carried out by using these parameters: E Value Hit filter: $1.0 \times 10^{-6}$; Annotation cut off: 55; GO weight: 5 . The prediction of presence of mitochondrial targeting pre-sequence in differential proteomes of both mutants was performed using MitoFates [77].

\subsection{Immunoblotting Analysis}

Immunoblotting analysis was performed on protein extracts derived from roots of 14 day-old plants of wild type, as well as pld 1 1-1 and pld 1 1-2 mutants following published procedure [74]. Anti-synaptotagmin (PhytoAb; dilution 1:1000), anti-FeSOD (Agrisera; dilution 1:3000) and anti-UCP1 (Agrisera; dilution 1:1000) primary antibodies were used. Immunoblot analyses were carried out in three biological replicates. Differences in signal intensity between wild type and the mutants were statistically evaluated using Student's $t$-test $(p<0.05)$.

\subsection{Whole Mount Immunofluorescence Labelling}

Immunolocalization of SYT1 and UCP1 proteins in root wholemounts was carried out as published previously [78]. As primary antibodies, we have used the rabbit anti-synaptotagmin 1 antibody (PhytoAb; 1:200) and anti-UCP1 antibody (Agrisera; 1:200), while Alexa-Fluor 647 goat anti-rabbit IgG was exploited as secondary antibody. Microscopic observations were performed using the Zeiss 710 Confocal Laser Scanning Microscope platform (Carl Zeiss, Jena, Germany), using excitation lines at 405 and $561 \mathrm{~nm}$ from argon, HeNe, diode and diode pumped solid-state lasers. ZEN 2010 software (Carl Zeiss) was used for post-processing, default deconvolution and quantification of fluorescence intensity. Additionally, Photoshop 6.0/CS, and Microsoft PowerPoint softwares were used to process the obtained images.

\section{Conclusions}

Based on this proteomic analysis, PLD $\alpha 1$ is a protein which in addition to its well-known functions in ABA signalling and cytoskeleton organization, important for the homeostasis of proteins involved in mitochondrial protein import, vesicular trafficking and glucosinolate biosynthesis.

Supplementary Materials: Supplementary materials can be found at http:/ /www.mdpi.com/1422-0067/20/1/82/s1.

Author Contributions: J.Š. conceived and coordinated the experiments and helped to evaluate data, T.T., T.P., O.Š. and P.V. made analyses and experiments, T.T. and J.Š. wrote the manuscript. All authors reviewed the manuscript.

Funding: This research was funded by Czech Science Foundation GAČR, grant number 16-22044S; the European Regional Development Fund OPVVV project "Plants as a tool for sustainable development" number 
CZ.02.1.01/0.0/16_019/0000827 supporting Excellent Research at CRH, USDA NIFA award \#58-6066-6-059 and NIH award \#USM-GR05802-03.

Acknowledgments: The mass spectrometry proteomics analysis was performed at the Institute for Genomics, Biocomputing and Biotechnology, Mississippi State University, with partial support from the Mississippi Agriculture and Forestry Experimental Station.

Conflicts of Interest: The authors declare no conflict of interest. The funders had no role in the design of the study; in the collection, analyses, or interpretation of data; in the writing of the manuscript, or in the decision to publish the results.

\section{References}

1. Wang, X. (Ed.) Phospholipases in Plant Signaling; Signaling and Communication in Plants; Springer: Berlin/Heidelberg, Germany, 2014; Volume 20, ISBN 978-3-642-42010-8.

2. Hong, Y.; Zhao, J.; Guo, L.; Kim, S.-C.; Deng, X.; Wang, G.; Zhang, G.; Li, M.; Wang, X. Plant phospholipases $\mathrm{D}$ and $\mathrm{C}$ and their diverse functions in stress responses. Prog. Lipid Res. 2016, 62, 55-74. [CrossRef] [PubMed]

3. Zhang, Q.; Lin, F.; Mao, T.; Nie, J.; Yan, M.; Yuan, M.; Zhang, W. Phosphatidic acid regulates microtubule organization by interacting with MAP65-1 in response to salt stress in Arabidopsis. Plant Cell 2012, 24, 4555-4576. [CrossRef] [PubMed]

4. Testerink, C.; Munnik, T. Molecular, cellular, and physiological responses to phosphatidic acid formation in plants. J. Exp. Bot. 2011, 62, 2349-2361. [CrossRef] [PubMed]

5. Zhang, W.; Qin, C.; Zhao, J.; Wang, X. Phospholipase D alpha 1-derived phosphatidic acid interacts with ABI1 phosphatase 2C and regulates abscisic acid signaling. Proc. Natl. Acad. Sci. USA 2004, 101, 9508-9513. [CrossRef] [PubMed]

6. Devaiah, S.P.; Roth, M.R.; Baughman, E.; Li, M.; Tamura, P.; Jeannotte, R.; Welti, R.; Wang, X. Quantitative profiling of polar glycerolipid species from organs of wild-type Arabidopsis and a PHOSPHOLIPASE D $\alpha 1$ knockout mutant. Phytochemistry 2006, 67, 1907-1924. [CrossRef] [PubMed]

7. Gao, H.-B.; Chu, Y.-J.; Xue, H.-W. Phosphatidic Acid (PA) Binds PP2AA1 to Regulate PP2A Activity and PIN1 Polar Localization. Mol. Plant 2013, 6, 1692-1702. [CrossRef] [PubMed]

8. Boutté, Y.; Moreau, P. Modulation of endomembranes morphodynamics in the secretory/retrograde pathways depends on lipid diversity. Curr. Opin. Plant Biol. 2014, 22, 22-29. [CrossRef]

9. Dhonukshe, P.; Laxalt, A.M.; Goedhart, J.; Gadella, T.W.J.; Munnik, T. Phospholipase d activation correlates with microtubule reorganization in living plant cells. Plant Cell 2003, 15, 2666-2679. [CrossRef]

10. Pleskot, R.; Potocký, M.; Pejchar, P.; Linek, J.; Bezvoda, R.; Martinec, J.; Valentová, O.; Novotná, Z.; Zárský, V. Mutual regulation of plant phospholipase D and the actin cytoskeleton. Plant J. 2010, 62, 494-507. [CrossRef]

11. Pleskot, R.; Li, J.; Žárský, V.; Potocký, M.; Staiger, C.J. Regulation of cytoskeletal dynamics by phospholipase D and phosphatidic acid. Trends Plant Sci. 2013, 18, 496-504. [CrossRef]

12. Novák, D.; Vadovič, P.; Ovečka, M.; Šamajová, O.; Komis, G.; Colcombet, J.; Šamaj, J. Gene expression pattern and protein localization of Arabidopsis Phospholipase D Alpha 1 revealed by advanced light-sheet and super-resolution microscopy. Front. Plant Sci. 2018, 9, 371. [CrossRef] [PubMed]

13. Mishra, G.; Zhang, W.; Deng, F.; Zhao, J.; Wang, X. A bifurcating pathway directs abscisic acid effects on stomatal closure and opening in Arabidopsis. Science 2006, 312, 264-266. [CrossRef] [PubMed]

14. Zhang, Y.; Zhu, H.; Zhang, Q.; Li, M.; Yan, M.; Wang, R.; Wang, L.; Welti, R.; Zhang, W.; Wang, X. Phospholipase D $\alpha 1$ and Phosphatidic Acid Regulate NADPH Oxidase Activity and Production of Reactive Oxygen Species in ABA-Mediated Stomatal Closure in Arabidopsis. Plant Cell 2009, 21, 2357-2377. [CrossRef] [PubMed]

15. Guo, L.; Mishra, G.; Markham, J.E.; Li, M.; Tawfall, A.; Welti, R.; Wang, X. Connections between sphingosine kinase and phospholipase D in the abscisic acid signaling pathway in Arabidopsis. J. Biol. Chem. 2012, 287, 8286-8296. [CrossRef] [PubMed]

16. Roy Choudhury, S.; Pandey, S. The role of PLD $\alpha 1$ in providing specificity to signal-response coupling by heterotrimeric G-protein components in Arabidopsis. Plant J. 2016, 86, 50-61. [CrossRef] [PubMed]

17. Roy Choudhury, S.; Pandey, S. Phosphatidic acid binding inhibits RGS1 activity to affect specific signaling pathways in Arabidopsis. Plant J. 2017, 90, 466-477. [CrossRef] [PubMed]

18. Hong, Y.; Zheng, S.; Wang, X. Dual functions of phospholipase Dalpha1 in plant response to drought. Mol. Plant 2008, 1, 262-269. [CrossRef] 
19. Huo, C.; Zhang, B.; Wang, H.; Wang, F.; Liu, M.; Gao, Y.; Zhang, W.; Deng, Z.; Sun, D.; Tang, W. Comparative Study of Early Cold-Regulated Proteins by Two-Dimensional Difference Gel Electrophoresis Reveals a Key Role for Phospholipase D $\alpha 1$ in Mediating Cold Acclimation Signaling Pathway in Rice. Mol. Cell. Proteom. 2016, 15, 1397-1411. [CrossRef]

20. Lu, S.; Bahn, S.C.; Qu, G.; Qin, H.; Hong, Y.; Xu, Q.; Zhou, Y.; Hong, Y.; Wang, X. Increased expression of phospholipase $\mathrm{D} \alpha 1$ in guard cells decreases water loss with improved seed production under drought in Brassica napus. Plant Biotechnol. J. 2013, 11, 380-389. [CrossRef]

21. Uraji, M.; Katagiri, T.; Okuma, E.; Ye, W.; Hossain, M.A.; Masuda, C.; Miura, A.; Nakamura, Y.; Mori, I.C.; Shinozaki, K.; et al. Cooperative function of PLD $\delta$ and PLD $\alpha 1$ in abscisic acid-induced stomatal closure in Arabidopsis. Plant Physiol. 2012, 159, 450-460. [CrossRef]

22. Devaiah, S.P.; Pan, X.; Hong, Y.; Roth, M.; Welti, R.; Wang, X. Enhancing seed quality and viability by suppressing phospholipase D in Arabidopsis: Phospholipase D in seed aging. Plant J. 2007, 50, $950-957$. [CrossRef] [PubMed]

23. Ufer, G.; Gertzmann, A.; Gasulla, F.; Röhrig, H.; Bartels, D. Identification and characterization of the phosphatidic acid-binding A. thaliana phosphoprotein PLDrp1 that is regulated by PLD $\alpha 1$ in a stress-dependent manner. Plant J. 2017, 92, 276-290. [CrossRef]

24. Gajiwala, K.S.; Burley, S.K. Winged helix proteins. Curr. Opin. Struct. Biol. 2000, 10, 110-116. [CrossRef]

25. Rodriguez, L.; Gonzalez-Guzman, M.; Diaz, M.; Rodrigues, A.; Izquierdo-Garcia, A.C.; Peirats-Llobet, M.; Fernandez, M.A.; Antoni, R.; Fernandez, D.; Marquez, J.A.; et al. C2-domain abscisic acid-related proteins mediate the interaction of PYR/PYL/RCAR abscisic acid receptors with the plasma membrane and regulate abscisic acid sensitivity in Arabidopsis. Plant Cell 2014, 26, 4802-4820. [CrossRef] [PubMed]

26. Zhang, Q.; Berkey, R.; Blakeslee, J.J.; Lin, J.; Ma, X.; King, H.; Liddle, A.; Guo, L.; Munnik, T.; Wang, X.; et al. Arabidopsis phospholipase D $\alpha 1$ and D $\delta$ oppositely modulate EDS1- and SA-independent basal resistance against adapted powdery mildew. J. Exp. Bot. 2018, 69, 3675-3688. [CrossRef] [PubMed]

27. Pleskot, R.; Pejchar, P.; Staiger, C.J.; Potocký, M. When fat is not bad: The regulation of actin dynamics by phospholipid signaling molecules. Front. Plant Sci. 2014, 5, 5. [CrossRef] [PubMed]

28. Steinborn, K. The Arabidopsis PILZ group genes encode tubulin-folding cofactor orthologs required for cell division but not cell growth. Genes Dev. 2002, 16, 959-971. [CrossRef] [PubMed]

29. Du, Y.; Cui, M.; Qian, D.; Zhu, L.; Wei, C.; Yuan, M.; Zhang, Z.; Li, Y. AtTFC B is involved in control of cell division. Front. Biosci. Elite Ed. 2010, 2, 752-763.

30. Dhonukshe, P.; Bargmann, B.O.R.; Gadella, T.W.J. Arabidopsis Tubulin Folding Cofactor B Interacts with $\alpha$-Tubulin In Vivo. Plant Cell Physiol. 2006, 47, 1406-1411. [CrossRef]

31. Gu, Y.; Deng, Z.; Paredez, A.R.; DeBolt, S.; Wang, Z.-Y.; Somerville, C. Prefoldin 6 is required for normal microtubule dynamics and organization in Arabidopsis. Proc. Natl. Acad. Sci. USA 2008, 105, 18064-18069. [CrossRef]

32. Nishimura, N.; Sarkeshik, A.; Nito, K.; Park, S.-Y.; Wang, A.; Carvalho, P.C.; Lee, S.; Caddell, D.F.; Cutler, S.R.; Chory, J.; et al. PYR/PYL/RCAR family members are major in-vivo ABI1 protein phosphatase 2C-interacting proteins in Arabidopsis. Plant J. Cell Mol. Biol. 2010, 61, 290-299. [CrossRef] [PubMed]

33. Postaire, O.; Tournaire-Roux, C.; Grondin, A.; Boursiac, Y.; Morillon, R.; Schäffner, A.R.; Maurel, C. A PIP1 aquaporin contributes to hydrostatic pressure-induced water transport in both the root and rosette of Arabidopsis. Plant Physiol. 2010, 152, 1418-1430. [CrossRef] [PubMed]

34. McLoughlin, F.; Arisz, S.A.; Dekker, H.L.; Kramer, G.; de Koster, C.G.; Haring, M.A.; Munnik, T.; Testerink, C. Identification of novel candidate phosphatidic acid-binding proteins involved in the salt-stress response of Arabidopsis thaliana roots. Biochem. J. 2013, 450, 573-581. [CrossRef] [PubMed]

35. Bellati, J.; Champeyroux, C.; Hem, S.; Rofidal, V.; Krouk, G.; Maurel, C.; Santoni, V. Novel Aquaporin Regulatory Mechanisms Revealed by Interactomics. Mol. Cell. Proteom. 2016, 15, 3473-3487. [CrossRef] [PubMed]

36. Wang, Y.; Carrie, C.; Giraud, E.; Elhafez, D.; Narsai, R.; Duncan, O.; Whelan, J.; Murcha, M.W. Dual location of the mitochondrial preprotein transporters B14.7 and Tim23-2 in complex I and the TIM17:23 complex in Arabidopsis links mitochondrial activity and biogenesis. Plant Cell 2012, 24, 2675-2695. [CrossRef] [PubMed]

37. Neupert, W. A Perspective on Transport of Proteins into Mitochondria: A Myriad of Open Questions. J. Mol. Biol. 2015, 427, 1135-1158. [CrossRef] [PubMed] 
38. Teixeira, P.F.; Glaser, E. Processing peptidases in mitochondria and chloroplasts. Biochim. Biophys. Acta Mol. Cell Res. 2013, 1833, 360-370. [CrossRef] [PubMed]

39. Van Aken, O.; Whelan, J.; Van Breusegem, F. Prohibitins: Mitochondrial partners in development and stress response. Trends Plant Sci. 2010, 15, 275-282. [CrossRef]

40. Piechota, J.; Bereza, M.; Sokołowska, A.; Suszyński, K.; Lech, K.; Jańska, H. Unraveling the functions of type II-prohibitins in Arabidopsis mitochondria. Plant Mol. Biol. 2015, 88, 249-267. [CrossRef]

41. Ahn, C.S.; Lee, J.H.; Reum Hwang, A.; Kim, W.T.; Pai, H.-S. Prohibitin is involved in mitochondrial biogenesis in plants. Plant J. 2006, 46, 658-667. [CrossRef]

42. Donaldson, J.G. Phospholipase D in endocytosis and endosomal recycling pathways. Biochim. Biophys. Acta 2009, 1791, 845-849. [CrossRef] [PubMed]

43. Antonescu, C.N.; Danuser, G.; Schmid, S.L. Phosphatidic Acid Plays a Regulatory Role in Clathrin-mediated Endocytosis. Mol. Biol. Cell 2010, 21, 2944-2952. [CrossRef]

44. Li, G.; Xue, H.-W. Arabidopsis PLD 2 Regulates Vesicle Trafficking and Is Required for Auxin Response. Plant Cell 2007, 19, 281-295. [CrossRef] [PubMed]

45. Roth, M.G. Molecular mechanisms of PLD function in membrane traffic. Traffic 2008, 9, 1233-1239. [CrossRef] [PubMed]

46. Thakur, R.; Panda, A.; Coessens, E.; Raj, N.; Yadav, S.; Balakrishnan, S.; Zhang, Q.; Georgiev, P.; Basak, B.; Pasricha, R.; et al. Phospholipase D activity couples plasma membrane endocytosis with retromer dependent recycling. eLife 2016, 5, e18515. [CrossRef] [PubMed]

47. Schumacher, K.; Krebs, M. The V-ATPase: Small cargo, large effects. Curr. Opin. Plant Biol. 2010, 13, 724-730. [CrossRef] [PubMed]

48. Fujiwara, M.; Uemura, T.; Ebine, K.; Nishimori, Y.; Ueda, T.; Nakano, A.; Sato, M.H.; Fukao, Y. Interactomics of Qa-SNARE in Arabidopsis thaliana. Plant Cell Physiol. 2014, 55, 781-789. [CrossRef]

49. Mayer, A.; Wickner, W.; Haas, A. Sec18p (NSF)-Driven Release of Sec17p ( $\alpha$-SNAP) Can Precede Docking and Fusion of Yeast Vacuoles. Cell 1996, 85, 83-94. [CrossRef]

50. Wang, T.; Li, L.; Hong, W. SNARE proteins in membrane trafficking. Traffic 2017, 18, 767-775. [CrossRef]

51. Uemura, T.; Ueda, T.; Ohniwa, R.L.; Nakano, A.; Takeyasu, K.; Sato, M.H. Systematic analysis of SNARE molecules in Arabidopsis: Dissection of the post-Golgi network in plant cells. Cell Struct. Funct. 2004, 29, 49-65. [CrossRef]

52. Wang, C.; Yan, X.; Chen, Q.; Jiang, N.; Fu, W.; Ma, B.; Liu, J.; Li, C.; Bednarek, S.Y.; Pan, J. Clathrin Light Chains Regulate Clathrin-Mediated Trafficking, Auxin Signaling, and Development in Arabidopsis. Plant Cell 2013, 25, 499-516. [CrossRef] [PubMed]

53. Fan, L.; Li, R.; Pan, J.; Ding, Z.; Lin, J. Endocytosis and its regulation in plants. Trends Plant Sci. 2015, 20, 388-397. [CrossRef] [PubMed]

54. Yamaoka, S.; Shimono, Y.; Shirakawa, M.; Fukao, Y.; Kawase, T.; Hatsugai, N.; Tamura, K.; Shimada, T.; Hara-Nishimura, I. Identification and dynamics of Arabidopsis adaptor protein-2 complex and its involvement in floral organ development. Plant Cell 2013, 25, 2958-2969. [CrossRef] [PubMed]

55. Zelazny, E.; Santambrogio, M.; Pourcher, M.; Chambrier, P.; Berne-Dedieu, A.; Fobis-Loisy, I.; Miège, C.; Jaillais, Y.; Gaude, T. Mechanisms Governing the Endosomal Membrane Recruitment of the Core Retromer in Arabidopsis. J. Biol. Chem. 2013, 288, 8815-8825. [CrossRef] [PubMed]

56. Kang, H.; Kim, S.Y.; Song, K.; Sohn, E.J.; Lee, Y.; Lee, D.W.; Hara-Nishimura, I.; Hwang, I. Trafficking of Vacuolar Proteins: The Crucial Role of Arabidopsis Vacuolar Protein Sorting 29 in Recycling Vacuolar Sorting Receptor. Plant Cell 2012, 24, 5058-5073. [CrossRef] [PubMed]

57. Nodzyński, T.; Feraru, M.I.; Hirsch, S.; De Rycke, R.; Niculaes, C.; Boerjan, W.; Van Leene, J.; De Jaeger, G.; Vanneste, S.; Friml, J. Retromer Subunits VPS35A and VPS29 Mediate Prevacuolar Compartment (PVC) Function in Arabidopsis. Mol. Plant 2013, 6, 1849-1862. [CrossRef]

58. Hino, T.; Tanaka, Y.; Kawamukai, M.; Nishimura, K.; Mano, S.; Nakagawa, T. Two Sec13p Homologs, AtSec13A and AtSec13B, Redundantly Contribute to the Formation of COPII Transport Vesicles in Arabidopsis thaliana. Biosci. Biotechnol. Biochem. 2011, 75, 1848-1852. [CrossRef]

59. Fridmann-Sirkis, Y.; Siniossoglou, S.; Pelham, H.R.B. TMF is a golgin that binds Rab6 and influences Golgi morphology. BMC Cell Biol. 2004, 5, 18. [CrossRef]

60. Latijnhouwers, M.; Gillespie, T.; Boevink, P.; Kriechbaumer, V.; Hawes, C.; Carvalho, C.M. Localization and domain characterization of Arabidopsis golgin candidates. J. Exp. Bot. 2007, 58, 4373-4386. [CrossRef] 
61. Wang, P.; Richardson, C.; Hawkins, T.J.; Sparkes, I.; Hawes, C.; Hussey, P.J. Plant VAP27 proteins: Domain characterization, intracellular localization and role in plant development. New Phytol. 2016, 210, 1311-1326. [CrossRef]

62. Saravanan, R.S.; Slabaugh, E.; Singh, V.R.; Lapidus, L.J.; Haas, T.; Brandizzi, F. The targeting of the oxysterol-binding protein ORP3a to the endoplasmic reticulum relies on the plant VAP33 homolog PVA12. Plant J. Cell Mol. Biol. 2009, 58, 817-830. [CrossRef] [PubMed]

63. Siao, W.; Wang, P.; Voigt, B.; Hussey, P.J.; Baluska, F. Arabidopsis SYT1 maintains stability of cortical endoplasmic reticulum networks and VAP27-1-enriched endoplasmic reticulum-plasma membrane contact sites. J. Exp. Bot. 2016, 67, 6161-6171. [CrossRef] [PubMed]

64. Takáč, T.; Pechan, T.; Richter, H.; Müller, J.; Eck, C.; Böhm, N.; Obert, B.; Ren, H.; Niehaus, K.; Šamaj, J. Proteomics on brefeldin A-treated Arabidopsis roots reveals profilin 2 as a new protein involved in the cross-talk between vesicular trafficking and the actin cytoskeleton. J. Proteome Res. 2011, 10, 488-501. [CrossRef]

65. Takáč, T.; Pechan, T.; Šamajová, O.; Ovečka, M.; Richter, H.; Eck, C.; Niehaus, K.; Šamaj, J. Wortmannin treatment induces changes in Arabidopsis root proteome and post-Golgi compartments. J. Proteome Res. 2012, 11, 3127-3142. [CrossRef] [PubMed]

66. Janda, M.; Šašek, V.; Chmelařová, H.; Andrejch, J.; Nováková, M.; Hajšlová, J.; Burketová, L.; Valentová, O. Phospholipase D affects translocation of NPR1 to the nucleus in Arabidopsis thaliana. Front. Plant Sci. 2015, 6, 59. [CrossRef]

67. Kravets, V.S.; Kretinin, S.V.; Kolesnikov, Y.S.; Getman, I.A.; Romanov, G.A. Cytokinins evoke rapid activation of phospholipase D in sensitive plant tissues. Dokl. Biochem. Biophys. 2009, 428, 264-267. [CrossRef] [PubMed]

68. Fan, L.; Zheng, S.; Wang, X. Antisense suppression of phospholipase D alpha retards abscisic acid- and ethylene-promoted senescence of postharvest Arabidopsis leaves. Plant Cell 1997, 9, 2183. [CrossRef]

69. Testerink, C.; Larsen, P.B.; van der Does, D.; van Himbergen, J.A.J.; Munnik, T. Phosphatidic acid binds to and inhibits the activity of Arabidopsis CTR1. J. Exp. Bot. 2007, 58, 3905-3914. [CrossRef]

70. Malka, S.K.; Cheng, Y. Possible Interactions between the Biosynthetic Pathways of Indole Glucosinolate and Auxin. Front. Plant Sci. 2017, 8, 2131. [CrossRef]

71. Sønderby, I.E.; Geu-Flores, F.; Halkier, B.A. Biosynthesis of glucosinolates-gene discovery and beyond. Trends Plant Sci. 2010, 15, 283-290. [CrossRef]

72. Skirycz, A.; Reichelt, M.; Burow, M.; Birkemeyer, C.; Rolcik, J.; Kopka, J.; Zanor, M.I.; Gershenzon, J.; Strnad, M.; Szopa, J.; et al. DOF transcription factor AtDof1.1 (OBP2) is part of a regulatory network controlling glucosinolate biosynthesis in Arabidopsis. Plant J. Cell Mol. Biol. 2006, 47, 10-24. [CrossRef] [PubMed]

73. Petersen, A.; Wang, C.; Crocoll, C.; Halkier, B.A. Biotechnological approaches in glucosinolate production. J. Integr. Plant Biol. 2018, 60, 1231-1248. [CrossRef] [PubMed]

74. Takáč, T.; Šamajová, O.; Pechan, T.; Luptovčiak, I.; Šamaj, J. Feedback microtubule control and microtubule-actin cross-talk in arabidopsis revealed by integrative proteomic and cell biology analysis of KATANIN 1 mutants. Mol. Cell. Proteom. 2017, 16, 1591-1609. [CrossRef] [PubMed]

75. Takáč, T.; Vadovič, P.; Pechan, T.; Luptovčiak, I.; Šamajová, O.; Šamaj, J. Comparative proteomic study of Arabidopsis mutants mpk4 and mpk6. Sci. Rep. 2016, 6, 28306. [CrossRef] [PubMed]

76. Conesa, A.; Götz, S. Blast2GO: A comprehensive suite for functional analysis in plant genomics. Int. J. Plant Genom. 2008, 2008, 619832. [CrossRef]

77. Fukasawa, Y.; Tsuji, J.; Fu, S.-C.; Tomii, K.; Horton, P.; Imai, K. MitoFates: Improved prediction of mitochondrial targeting sequences and their cleavage sites. Mol. Cell. Proteom. 2015, 14, 1113-1126. [CrossRef] [PubMed]

78. Šamajová, O.; Komis, G.; Šamaj, J. Immunofluorescent Localization of MAPKs and Colocalization with Microtubules in Arabidopsis Seedling Whole-Mount Probes. In Plant MAP Kinases: Methods and Protocols; Komis, G., Šamaj, J., Eds.; Springer: New York, NY, USA, 2014; pp. 107-115. ISBN 978-1-4939-0922-3.

(C) 2018 by the authors. Licensee MDPI, Basel, Switzerland. This article is an open access article distributed under the terms and conditions of the Creative Commons Attribution (CC BY) license (http:/ / creativecommons.org/licenses/by/4.0/). 